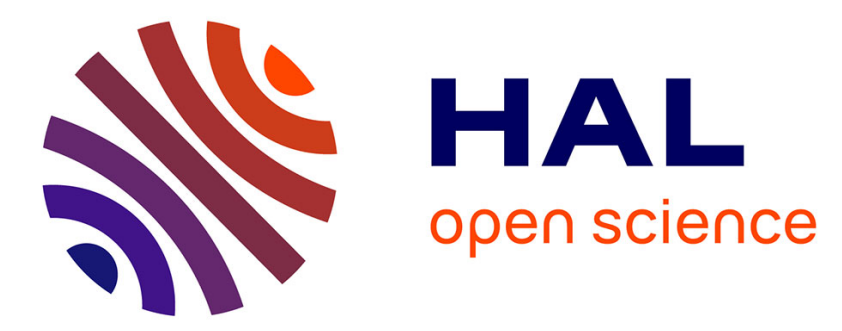

\title{
Determination of Effective Linewidth Using FMR Line Shape Analysis
}

\author{
Arunima Srivastava, M. Patni, B. Chaturvedi
}

\section{To cite this version:}

Arunima Srivastava, M. Patni, B. Chaturvedi. Determination of Effective Linewidth Using FMR Line Shape Analysis. Journal de Physique IV Proceedings, 1997, 07 (C1), pp.C1-443-C1-444. 10.1051/jp4:19971179 . jpa-00254827

\section{HAL Id: jpa-00254827 https://hal.science/jpa-00254827}

Submitted on 1 Jan 1997

HAL is a multi-disciplinary open access archive for the deposit and dissemination of scientific research documents, whether they are published or not. The documents may come from teaching and research institutions in France or abroad, or from public or private research centers.
L'archive ouverte pluridisciplinaire HAL, est destinée au dépôt et à la diffusion de documents scientifiques de niveau recherche, publiés ou non, émanant des établissements d'enseignement et de recherche français ou étrangers, des laboratoires publics ou privés. 


\title{
Determination of Effective Linewidth Using FMR Line Shape Analysis
}

\author{
A.K. Srivastava, M.J. Patni and B.K. Chaturvedi* \\ Department of Metalurgical Engineering and Materials Science, IIT, Powai, Bombay 400 076, India \\ * SAMEER, IIT Campus, Powai, Bombay, India
}

\begin{abstract}
A new technique of measuring the effective linewidth using FMR line shape analysis has been proposed. The observed FMR spectra of low loss garnets were best fitted to a Lorentzian. $\Delta \mathrm{H}_{\mathrm{eff}}$ was determined by measuring linewidih deviations from the Lorentzian line shape.
\end{abstract}

\section{INTRODUCTION}

Effective linewidth $\left(\Delta \mathrm{H}_{\mathrm{eff}}\right)$ is usually determined from microwave susceptibility data. The ferromagnetic resonance absorption curve is represented by [1],

$$
4 \pi \chi_{e}^{\prime \prime}=\frac{\gamma\left(4 \pi M_{s}\right) \eta}{\left(\gamma H_{0}-\omega\right)^{2}+\eta^{2}}
$$

where $\chi_{\mathrm{e}}$ is the imaginary part of the diagonal element of susceptibility tensor corresponding to the direction of the microwave field. If $\eta$ and $\gamma$ are independent of $H_{0}$, the curve will be a Lorentzian centered at $H_{\circ}=\omega / \gamma$ with a linewidth, $\Delta \mathbf{H}=2 \eta / \gamma$. However, the curve whose line profile is not Lorentzian can be represented by eq. (1) only when $\eta$ and $\gamma$ are taken to be field dependent quantities. As $\gamma$ does not change appreciably with $H_{0}$, the field dependence of $\eta$, i.e., $\Delta H_{\text {eff }}$ provides a measure of the departure of the absorption curve from a Lorentzian line shape. In the present study, to evaluate the $\Delta H_{\text {eff }}$ of gadolinium doped calcium vanadium garnets, the FMR absorption curves are first best fitted to a Lorentzian. After optimizing the fitting of the Lorentzian curve to the experimental data, deviations were observed from the theoretical curve, specially in the wings. A computer program was then used to fit a $\Delta \mathbf{H}$ at a given field such that the deviation is removed keeping the resonance field and the area of the curve constant in the original Lorentzian. When this is carried out at an interval of $2 \mathrm{Oe}$ in the static field, a plot of $\Delta \mathrm{H}_{\text {eff }}$ with static field is obtained, which has a shape very similar to the measurements of $\Delta \mathrm{H}_{\text {eff }}$ reported in literature [2]. It has two peaks, one relating to anisotropy and the other to porosity.

\section{MEASUREMENT TECHNIQUE}

Gadolinium substituted calcium vanadium garnets $\left[\mathrm{Y}_{3-2 x-y-z} \mathrm{Ca}_{2 x+y} \mathrm{Gd}_{z} \mathrm{Fe}_{5-\mathrm{x}-\mathrm{y}} \mathrm{Zr}_{\mathrm{y}} \mathrm{V}_{\mathrm{x}} \mathrm{O}_{12}\right.$ with $\mathrm{x}=0.4, \mathrm{y}=0.6$ and $z=0.8$, 1.0, 1.2 and 1.4] having $4 \pi \mathrm{M}_{\mathrm{s}}$ between 800 and $1200 \mathrm{G}$ and $\Delta H$ less than 30 Oe were prepared by citrate-gel route. The samples are coded as CIT-(z). Resonance spectra of differential absorption curve with respect to the applied field of these samples were taken at X-band ( $-9.3 \mathrm{GH} z)$ using a VARIAN E-112 ESR spectrometer. The data was then fitted to a differential of Lorentzian,

$$
g^{\prime}(H)=\frac{A\left(H-H_{0}\right)}{\left(\Delta H_{1 / 2}^{2}+\left(H-H_{0}\right)^{2}\right)^{2}}
$$

A trial attempt is first made to fit experimental data to eq.(2) near resonance obtaining the best fit values of $A, H_{0}$ and $\Delta H$ The standard root mean square deviation from the Lorentzian curve is calculated and then these values are made to change slightly to minimize the deviation. After so fixing the new values of $A, H_{0}$ and $\Delta H$, difference between the theoretical and experimental value is noted at fields at an interval of $2 \mathrm{Oe}$, and $\Delta H$ is varied till it exactly fits the experimental curve at that point. The new value of $\Delta H$ required to fit the experimental curve at steady field $H$ is the effective linewidth at that field [1].

\section{RESULTS AND DISCUSSIONS}

Plots of $\Delta \mathrm{H}_{\mathrm{eff}}$ vs applied field for the four samples measured at room temperature are shown in Fig. (1). Two distinct peaks, 
ascribable as the anisotropy and porosity pcaks, are observed on either side of the main resonance field. The anisotropy peaks are almost the same for CIT-(0.8) and CIT-(1.0) and are much smaller than those of CIT-(1.2) and CIT-(1.4). The porosity peak increases with increasing porosity in these samples but not in a specific manner. In Fig. (2), a plot of effective linewidth against applied external field for CIT-(0.8) measured by the present technique is compared with that of $\mathrm{YCa}_{2} \mathrm{Fe}_{3.6} \mathrm{Sn}_{0.4} \mathrm{Ge}_{0.4} \mathrm{~V}_{0.6} \mathrm{O}_{12}$ (CaVGeSn) measured by means of a highly sensitivity susceptibility spectrometer by Inui [3]. Both curves were measured at room temperature and in the degenerate spin wave manifold region. The following inferences can be drawn:

1. The magnon manifold and other related characteristics of the present system and CaVGeSn garnet are given in Table - (1). The data on present system covers about $40 \%$ of the manifold while that on CaVGeSn garnet covers almosi $100 \%$. However there are remarkable similarities.

2. Both the curves show two maxima, one associated with anisotropy broadening while the other with porosity broadening. The former occurs at fields lower than the resonance field while the latter at a field higher than the resonance field.

3. The magnitude of the $\Delta \mathrm{H}_{\text {eff }}$ due to the two broadening mechanisms is almost the same in both the garnet systems.

4. On account of a much detailed study of $\Delta \mathrm{H}_{\text {eff }}$ variation at the interval of 2 Oe by our technique compared to that of Inui $[3]$, which is carried out at interval of nearly $50 \mathrm{Oc}$, there are greater details of the fine structure present in our case. For example, the porosity peak shows two closely spaced peaks for the present system while it is absent in CaVGeSn garnet system. This is attributed to the randon distribution of Gd-ions on c-sublattice. With increase in Gd-concentration, the two peaks merge as shown in Fig. (1).

5. The variation of $\Delta \mathrm{H}_{\text {eff }}$ with $\mathrm{H}$ has been computed using a least square fit program. The data points for each set are in the range of 70 to 80 . The root mean square deviation is \pm 1 Oe.

\section{CONCLUSIONS}

A cost effective technique to measure effective linewidth in the spin wave manifold region has been proposed. The method is based on the line shape analysis of the FMR spectra and shows greater details on loss characteristics of the specimen. This technique will have to be tried on other systems to make it widely acceptable.

\section{REFERENCES}

[1] Patton C.E. and Kohane T., Rev. Sci. Instr., 43 (1972) 76

[2] Vrehen Q.H.F., IEEE Trans. Magnetics, MAG-4 (1968) 479

[3] Inui T., Magnetics, IECE' 76/4, 59-C (1976) 239

TABLE - (1)

Limits of the spin wave manifold for CIT-(0.8) and CaVGeSn [3]

\begin{tabular}{|ccccc|}
\hline System & $4 \pi \mathrm{M}_{\mathbf{s}}(\mathbf{G})$ & Lower manifold field limit & Upper manifold field limit & Frequency of measurement (GHz) \\
\hline CIT-(0.8) & 1080 & $3084 \mathrm{Oe}$ & $3599 \mathrm{Oe}$ & 9.07 \\
\hline CaVGeSn & 400 & $3257 \mathrm{Oe}$ & $3451 \mathrm{Oe}$ & 9.29 \\
\hline
\end{tabular}

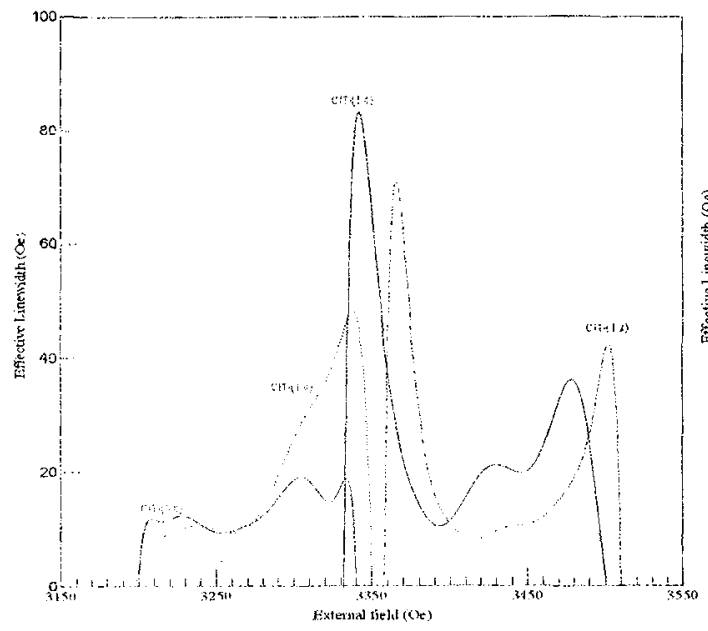

Fig. (1) Plot of $\Lambda H_{t f f}$ ws applied ficld neasured using present technique

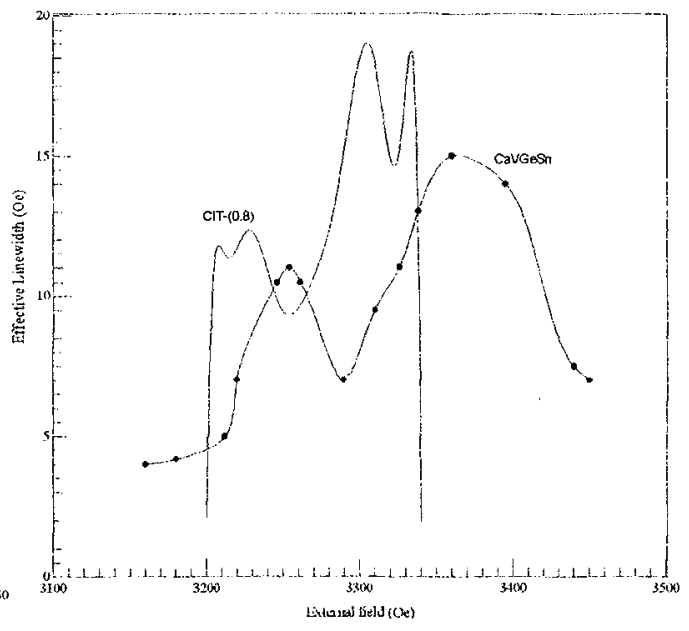

Fig. (2) Plot of $\mathrm{AH}_{\text {eff }}$ vs applied field for CII-(0.8) using present technique, and, of CaVGeSn measured by conventional technique [3] 